\title{
PASAR PUBLIK MAYESTIK
}

\author{
Sebastian Tanuwidjaja ${ }^{1)}$, Sidhi Wiguna Teh ${ }^{21}$ \\ 1)Program Studi S1 Arsitektur, Fakultas Teknik, Universitas Tarumanagara, \\ sebastiantanuwidjaja@yahoo.com \\ 2)Program Studi S1 Arsitektur, Fakultas Teknik, Universitas Tarumanagara, sidhi@ft.untar.ac.id
}

Masuk: 14-07-2020, revisi: 28-07-2020, diterima untuk diterbitkan: 24-09-2020

\begin{abstract}
Abstrak
Sebuah tempat ketiga sangat dibutuhkan oleh berbagai kalangan manusia. Hal ini berfungsi sebagai hiburan terhadap rutinitas kegiatan manusia pada masa modern. Dimana kehidupan mereka terpecah pada sebuah tempat pertama yang menjadi rumah dan tempat kedua yang menjadi tempat kegiatan bekerja mereka sehari-hari. Lokasi Proyek terletak di Jalan Tebah, Kebayoran Baru yang terkenal dengan area perdagangan. Aktivitas di sekitar tapak didominasi aktivitas perdagangan, aktivitas lainnya terdapat aktivitas sekolah, perkantoran dan perumahan. Tujuan dari proyek ini adalah untuk memfasilitasi masyarakat untuk bersosialisasi dari semua kalangan melalui aktivitas perdagangan, peran masyarakat pada proyek ini adalah sebagai user yang terbagi menjadi peran pedagang yang bekerja sebagai wirausaha yang dan pembeli. Hal ini juga bertujuan mendukung program Sustainable Development Goals perihal kesetaraan status sosial. Manusia membutuhkan kebutuhan primer dan dengan gaya hidup manusia modern yang individualis akibat tuntutan pekerjaan yang memakan waktu, oleh sebab itu dibuatlah sebuah Pasar Publik Mayestik yang dapat mewadahi kebutuhan sandang dan pangan serta rekreasi dengan konsep tempat ketiga. Program pasar dibagi menjadi 2 bagian, yaitu area basah dan area kering. Dalam area basah terdapat program Food Street, Fresh Market, Mini Market, dan Bar, sedangkan pada area kering terdapat program Bazaar, Online Marketplace, dan Barbershop. Terdapat juga program lainnya untuk mendukung konsep tempat ketiga dan aktivitas pengembangan diri berupa Library, Artspace, Culinary Workshop, dan Public Space. Tempat ini dapat digunakan untuk semua kalangan manusia tanpa harus berbayar, dengan harapan dapat menyatukan manusia dari semua kalangan tanpa melihat status sosial masing-masing dan berinteraksi satu dengan lainnya seperti seharusnya.
\end{abstract}

\section{Kata kunci: Kebayoran Baru; Kebutuhan; Pasar; Tempat Ketiga}

\begin{abstract}
A third place is needed by various groups of human. This serves as entertainment for the routine of human activity in the modern times. Where Their lives are divided by the first place that becomes their home and the second place where they running daily work activities. The Project is located on Jalan Tebah, Kebayoran Baru which is famous for its trading. Activities around the site are dominated by trade activities, other activities are school, office and housing activities. The purpose of this project is to facilitate the community to socialize from all groups of people through trading activities, the role of the community in this project is as a user who is divided into the role of traders who work as entrepreneurs and buyers. It also aims to support the Sustainable Development Goals program regarding equality of social status. With an individualist lifestyle due to demands of timeconsuming work and humans need primary needs, therefore the Mayestik Public Market was formed to accommodate the needs of clothing and food and recreation with a third place concept. The market program is divided into 2 parts, namely wet and dry areas. In the wet area there are Food Street, Fresh Market, Mini Market and Bar, while in the dry area there are Bazaar, Online Marketplace, and Barbershop. There are also other programs to support the third place and selfdevelopment activities with Library, Artspace, Culinary Workshop, and Public Space. This place can be used for all people without paying, hoping to unite people from all groups of people without looking at each other's social status and interacting with one another as they should.
\end{abstract}

Keywords: Kebayoran Baru; Market; Needs; Third Place 


\section{PENDAHULUAN}

\section{Latar Belakang}

Manusia memiliki berbagai macam kebutuhan-kebutuhan dalam menjalani hidupnya yang harus terpenuhi, berbagai cara akan dilakukan demi memenuhi kebutuhan ini. Kebutuhan yang paling mendasar adalah kebutuhan primer yang meliputi kebutuhan akan pangan (makan), sandang (pakaian), dan papan (tempat tinggal). Kebutuhan lainnya yang dibutuhkan adalah kebutuhan akan sosialisasi dikarenakan manusia adalah makhluk sosial yang membutuhkan sesamanya untuk bertahan hidup. Pada masa kehidupan yang kita jalani saat ini, manusia pada umumnya menjalani pola kehidupan mereka melalui rutinitas keseharian mereka yang melibat kan dua titik atau tempat yang digolongkan sebagai; First Place yang merupakan sebuah tempat tinggal, rumah, atau keluarga, dan Second Place yang merupakan sebuah tempat dimana mereka melakukan kesibukan mereka, seperti bekerja, sekolah, kuliah, dan lainnya. Rutinitas ini nantinya akan menghasilkan sebuah stress bagi manusia. Dengan fenomena ini, manusia memerlukan sebuah Third Place dimana mereka dapat bersosialisasi, bersantai, dan melupakan sejenak segala rutinitas yang mereka jalani sehari-harinya. Manusia merupakan makhluk sosial, makhluk sosial merupakan zoon politicon, yang berarti menusia dikodratkan untuk hidup bermasyarakat dan berinteraksi satu sama lain, menurut Aristoteles.

Memang interaksi sosial dapat dilakukan di dalam First Place dan juga Second Place, tetapi di dalam kedua tempat tersebut terdapat sebuah struktur yang dapat melimitasi interaksi antar manusia di dalamnya, sehingga tidak dapat berinteraksi secara dalam dan bebas. Dari permasalahan tersebut maka ada baiknya apabila diantara tempat pertama mereka yaitu tempat tinggal dan tempat kedua mereka yaitu tempat bekerja dan beraktivitas memiliki sebuah wadah atau tempat ketiga sebagai sarana mereka untuk bersosialisasi dan me-refresh diri mereka masing - masing demi mempersiapkan hari esok yang memiliki beragam tantangan dan hal tak terduga lainnya tanpa harus dibatasi oleh ruang dan waktu. Wadah antara dua tempat tersebut secara awam harusnya dapat menaungi berbagai ekspresi dan problematika dari para maskyarakat yang ada di Kawasan tersebut, sekaligus dapat merubah pola pikir yang salah di masyarakat tersebut lewat pendekatan-pendekatan yang dilakukan lewat sebuah bangunan hingga sampai ke interaksi intim mereka masing-masing.

\section{Rumusan Permasalahan}

Pola hidup manusia moderen yang menuntut untuk bekerja demi memenuhi kebutuhan hidup yang cukup memakan waktu, secara tidak langsung mengurangi waktu mereka untuk berinteraksi atau bersosialisasi satu dengan yang lain, manusia lebih banyak menghabiskan waktu mereka untuk bekerja dalam rutinitas mereka. Kurangnya wadah interaksi sosial yang mumpuni untuk memenuhi kebutuhan interaksi sosial manusia akibat faktor lokasi ataupun fasilitas-fasilitas yang didalamnya untuk menyesuaikan gaya hidup manusia modern.

\section{Tujuan}

Menghasilkan sebuah wadah atau bangunan yang dapat mendorong tiap-tiap individu, baik individu yang tinggal ataupun bekerja di kawasan tersebut dan juga individu yang berasal dari luar kawasan tersebut, untuk berinteraksi dan bersosialisasi.

\section{KAJIAN LITERATUR}

\section{Third Space Theory (Homi K. Bhabha)}

Ide dari teori ini datang dari teori Hybridity (Homi K. Bhabha), mengacu dari karya Edward Said, menggambarkan munculnya bentuk budaya baru dari multikulturalisme. Dari pada melihat kolonialisme sebagai sesuatu dari masa lalu, Bhabha menunjukkan bagaimana sejarah dan budaya terus-menerus mempengaruhi masa sekarang, menuntut kita mengubah pemahaman kita tentang hubungan cross-cultural. Third Space bertindak sebagai wilayah ambigu yang 
berkembang ketika dua individu / budaya atau lebih berinteraksi. Ini "menantang perasaan kita tentang identitas historis budaya sebagai kekuatan penyeragaman, pemersatu, yang disahkan oleh masa lalu yang asli, tetap hidup dalam tradisi nasional masyarakat." Area wacana yang ambivalen ini, yang berfungsi sebagai situs untuk kondisi diskursif pengucapan, "menggeser narasi Barat yang ditulis dalam waktu serentak yang homogen." Bhabha mengklaim bahwa "pernyataan dan sistem budaya dibangun dalam ruang pelafalan yang kontradiktif dan ambivalen ini." Akibatnya, klaim hierarkis atas orisinalitas atau kemurnian budaya bawaan tidak valid. Pelafalan menyiratkan bahwa budaya tidak memiliki kekakuan dan bahkan tanda-tanda yang sama dapat disesuaikan, diterjemahkan, direhistorisasi, dan dibaca lagi.

\section{Thirdspace (Edward W. Soja)}

Edward Soja mengembangkan teori Thirdspace di mana "semuanya datang bersama ... subjektivitas dan obyektivitas, yang abstrak dan yang konkret, yang nyata dan yang dibayangkan, yang dapat diketahui dan yang tak terbayangkan, yang berulang dan yang berbeda, struktur dan agensi, struktur dan agensi, pikiran dan tubuh, kesadaran dan alam bawah sadar, disiplin dan transdisipliner, kehidupan sehari-hari dan sejarah tanpa akhir." Saat ia menjelaskan, "Saya mendefinisikan Thirdspace sebagai cara lain untuk memahami dan bertindak untuk mengubah spasial kehidupan manusia, sebuah mode berbeda dari kesadaran spasial kritis yang sesuai dengan ruang lingkup baru dan signifikansi yang dibawa dalam uji coba yang diseimbangkan kembali oleh para peneliti spasial - historisitas - sosialitas." Soja membangun Thirdspace dari percobaan spasial yang didirikan oleh Henri Lefebvre dalam The Production of Space dan konsep heterotopia Michel Foucault. Dia mensintesis teori-teori ini dengan karya pemikir postkolonial dari Gayatri Chakravorty Spivak untuk mengaitkan, Edward Said ke Homi K. Bhabha.

Soja menunjukkan kecenderungan ke arah mistisisme monadik di Thirdspace-nya. Dia merumuskan Thirdspace dengan analogi dengan Aleph, sebuah konsep ketakterbatasan spasial yang dikembangkan oleh Jorge Luis Borges. Thirdspace adalah konsep inklusif secara radikal yang mencakup epistemologi, ontologi, dan historisitas dalam gerakan terus-menerus di luar dualisme dan menuju "an-Other": seperti dijelaskan oleh Soja, "ketiga menghasilkan apa yang lebih baik disebut percobaanektum kumulatif yang secara radikal terbuka untuk perbedaan lain," ke perluasan berkelanjutan pengetahuan spasial." Thirdspace adalah konsep transenden yang terus berkembang untuk memasukkan" an-Other, "sehingga memungkinkan kontestasi dan negosiasi ulang batas dan identitas budaya. Soja di sini sangat mirip dengan Third Space Theory (Homi K. Bhabha), di mana "semua bentuk budaya terus-menerus berproses dalam hibriditas," yang "menggeser sejarah yang membentuknya, dan membentuk struktur otoritas baru, inisiatif politik baru. Proses hibriditas budaya memunculkan sesuatu yang berbeda, sesuatu yang baru dan tidak dapat dikenali, area baru negosiasi makna dan representasi."

\section{Space and Place}

Menurut Yi Fu Tuan, perbedaan antara 'Space' dan 'Place' dapat dijelaskan dengan dua cara yang berbeda, yaitu:

a. Secara langsung dan intim, misalnya melalui indera seperti penglihatan, penciuman, indera dan pendengaran.

b. Secara tidak langsung dan konseptual dimediasi oleh simbol, seni dll.

Space dapat digambarkan sebagai lokasi yang tidak memiliki koneksi sosial bagi manusia. Tidak ada nilai yang ditambahkan ke ruang ini. Menurutnya, itu adalah ruang terbuka, tetapi dapat ditandai dan dipertahankan terhadap penyusup. Tidak mengundang atau mendorong orang untuk mengisi ruang dengan menjadi kreatif, bersifat abstrak. Place lebih dari sekedar lokasi dan dapat digambarkan sebagai lokasi yang diciptakan oleh pengalaman manusia. Ukuran lokasi ini tidak masalah dan tidak terbatas. Itu bisa berupa kota, lingkungan, wilayah atau bahkan ruang 
kelas dan sebagainya. Sebenarnya Place ada dari Space yang dipenuhi dengan makna dan tujuan oleh pengalaman manusia di ruang khusus ini. Place adalah pusat di mana orang dapat memenuhi kebutuhan biologis di sana seperti makanan, air, dll.. Menurutnya, Place tidak ada dari batas-batas yang dapat diamati dan di samping ekspresi yang terlihat dari periode waktu tertentu. Contohnya adalah seni, monumen dan arsitektur.

\section{Third Place}

Third Place merupakan tempat yang mempertemukan berbagai macam masyarakat, dimana kegiatannya tidak terkait dengan rutinitas rumah (First Place) dan rutinitas pekerjaan (Second Place). Third Place diperlukan bagi semua orang karena merupakan tempat dimana orang dapat melepaskan kepenatan yang terjadi pada aktivitas keseharian mereka. Oldenburg mencatat bahwa Third Place memiliki setidaknya tujuh karakter ruang yang unik. Berikut merupakan karakteristik dari Third Place menurut Oldenburgh :

a. Neutral Ground

Pengguna Third Place tidak memiliki kewajiban untuk berada di tempat tersebut. Mereka tidak terikat secara finansial, politik, ataupun hokum dan mereka bebas untuk datang dan pergi sesuai keinginan mereka.

b. Level

Third Place tidak mementingkan status sosial dan ekonomi seorang individu dalam masyarakat. Menciptakan adanya rasa kesamaan di antara masing-masing penggunanya. Tidak ada persyaratan untuk berpartisipasi di Third Place.

c. Conversation is the Main Activity

Obrolan yang bersifat menyenangkan dan bahagia menjadi fokus tujuan utama dari aktivitas di tempat ini, meskipun tidak harus menjadi aktivitas satu-satunya. Nada percakapan biasanya ringan, nyaman, dan lucu. Kecerdasan dan sifat menyenangkan sangat dihargai.

d. Accesible and Accomodation

Third Place harus bersifat terbuka dan mudah diakses oleh penggunanya. Dan juga akomodatif, yang berarti memenuhi kebutuhan penggunanya, dan semua pengguna measa kebutuhannya terpenuhi.

e. The Regulars

Third Place pada umumnya memiliki beberapa pengunjung tetap yang memberi nada pada ruang, dan mengatur suasana dan karakteristik ruang. Pengunjung tetap juga mengundang pendatang baru ke Third Place, dan ada di sana untuk membantu seseorang yang baru terhadap tempat tersebut untuk merasa diterima.

f. A Low Profile

Third Place secara karakteristik sehat. Di dalam Third Place tidak berlebihan dan mulukmuluk, dan memiliki rasa seperti di rumah. Third Place tidak pernah sombong atau berpurapura, dan menerima semua individu dari berbagai lapisan masyarakat.

g. The Mood is Playful

Nada percakapan di Third Place tidak pernah ditandai ketegangan atau permusuhan. Sebaliknya, Third Place memiliki sifat yang menyenangkan, di mana percakapan yang cerdas dan candaan tidak hanya umum tetapi sangat dihargai.

Hal serupa juga dibahas dalam buku Sharing Cities : a Case for Truly Smart \& Sustainable Cities (2015) oleh Duncan McLaren dan Julian Agyeman. Akan tetapi, Julian Agyeman lebih memilih istilah Sharing Paradigm dimana pengguna didorong untuk berbagi tidak hanya untuk mengejar keuntungan seperti yang ada pada Sharing Economy, melainkan memiliki sebuah hasrat untuk membantu terhadap sebuah komunitas. Julian Agyeman juga berpendapat bahwa, pemimpin kota harus mendorong bentuk kegiatan berbagi yang lebih demokratis, dimana kegiatan didominasi oleh "pengguna" disbanding oleh "investor". 
Terdapat 4 "Flavors" dalam sharing, yaitu :

a. Informal dan Sociocultural, dimana kegiatan berbagi terorganisir secara langsung antara individunya.

b. Mediated, dimana kegiatan berbagi menggunakan pihak ketiga atau jaringan formal yang menghubungkan antara individunya.

c. Commercial, dimana kegiatan berbagi dilakukan karena termotivasi oleh uang atau untuk mengejar keuntungan, melalui perdagangan barang atau jasa.

d. Communal, dimana kegiatan berbagi dilakukan karena termotivasi dengan sebuah hasrat untuk membantu memenuhi kebutuhan sebuah komunitas.

\section{METODE}

Proses desain bermula dengan menemukan isu atau permasalahan, masih tidak berbentuk dan tidak memiliki arah. Setelah isu atau permasalahan ditemukan, dilanjutkan dengan memberikan ide. Agar ide tidak berbuah dengan hasil yang bersifat subjektif, maka didukung dengan teoriteori dan standar yang telah ada serta pencarian studi preseden terhadap proyek-proyek yang sudah terbangun. Ide dikembangkan menjadi program yang akan diwujudkan ke dalam aktivitasaktivitas utama dan pendukung. Dari program yang sudah dirancang, dibentuk kriteria-kriteria untuk melakukan pemilihan tapak.

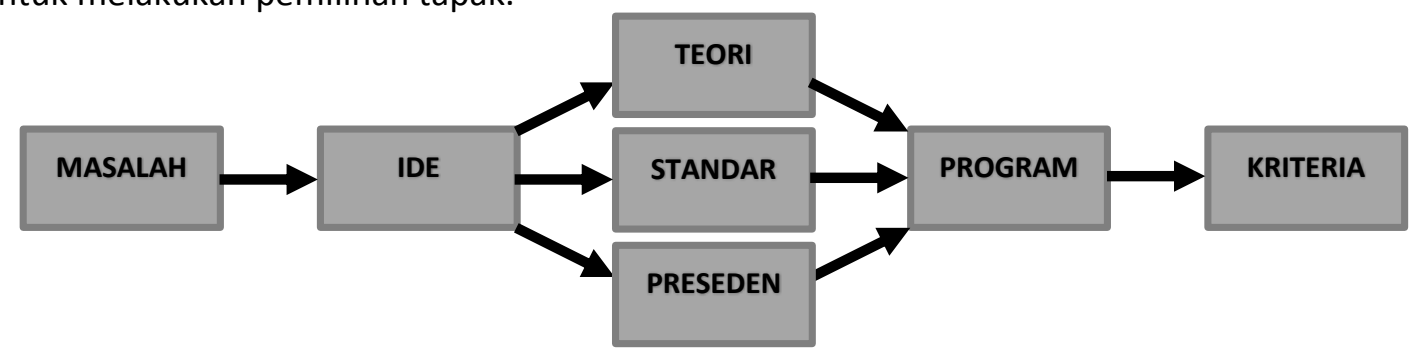

Gambar 1. Diagram Metode Perancangan Program

Sumber: Penulis, 2020

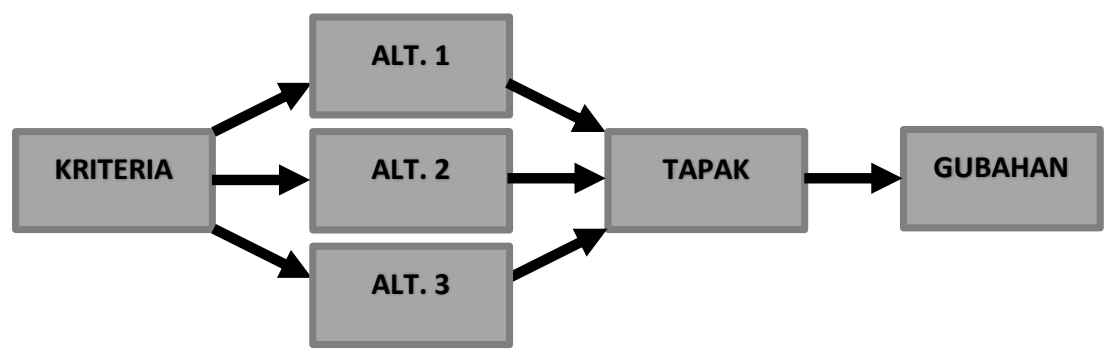

Gambar 2. Diagram Metode Pemilihan Tapak

Sumber: Penulis, 2020

Setelah program utama dan program pendukung telah dibentuk, maka dilakukan alternatif pemilihan tapak sebanyak 3 alternatif. Dari ketiga alternatif dibentuk kriteria atau poin-poin utama yang menjadi dasar untuk memilih tapak yang terbaik untuk program yang telah ditentukan. Dalam menentukan alternatif tapak, ditentukan kriteria-kriteria terhadap alternatif tapak yang nantinya akan mendukung operasional proyek dan konsep. Dalam hal ini, kriteria yang ditentukan antara lain adalah:

a. Lokasi Tapak

Selain lokasi, hal ini meliputi aksesibilitas dan orientasi tapak dan juga fasilitas dan aksesibilitas terhadap tapak.

b. Kependudukan

Data kependudukan pada tapak, meliputi jumlah penduduk dan pekerjaan atau mata pencaharian penduduk, serta karakteristik penduduk pada kawasan. 
c. Kegiatan

Merupakan pemetaan kegiatan dari tapak, aktivitas-aktivitas apa saja yang terjadi di dalam kawasan dan jam operasionalnya.

Setelah alternatif tapak dijabarkan, maka dilakukan penilaian untuk memilih tapak terbaik dari yang lainnya. Setelah tapak terbaik dipilih, langkah berikutnya melakukan analisa S.W.O.T. terhadap tapak terpilih untuk mengetahui kecocokan dan karakter program-program secara spesifik serta strategi dalam perancangan. Kemudian program yang sudah memiliki standar disesuaikan ke dalam tapak terpilih melalui analisa zoning secara 3 dimensi yang meliputi orientasi ruang dan sirkulasi pengguna dan servis yang kemudian menghasilkan gubahan massa. Setelah gubahan massa sudah dibentuk maka dilakukan pengerjaan terhadap gambar kerja denah, tampak dan potongan. Dilakukan juga analisa dan pemilihan material terhadap komponen bangunan. Material yang dipilih juga disesuaikan dengan konsep biophilic design agar tetap konsisten terhadap konsep bangunan.

\section{DISKUSI DAN HASIL}

Proyek dinamakan Pasar Publik Mayestik / Mayestik Public Market dengan konsep dasar atau platform Social Economy dimana kegiatan perdagangan sebagai pendorong terjadinya interaksi sosial antar manusia. Kegiatan perdagangan itu sendiri bertema kebutuhan primer manusia yaitu sandang, pangan, dan papan. Dikarenakan kebutuhan akan papan pada umumnya sudah terpenuhi melalui first place, maka lebih difokuskan pada sandang dan pangan saja.

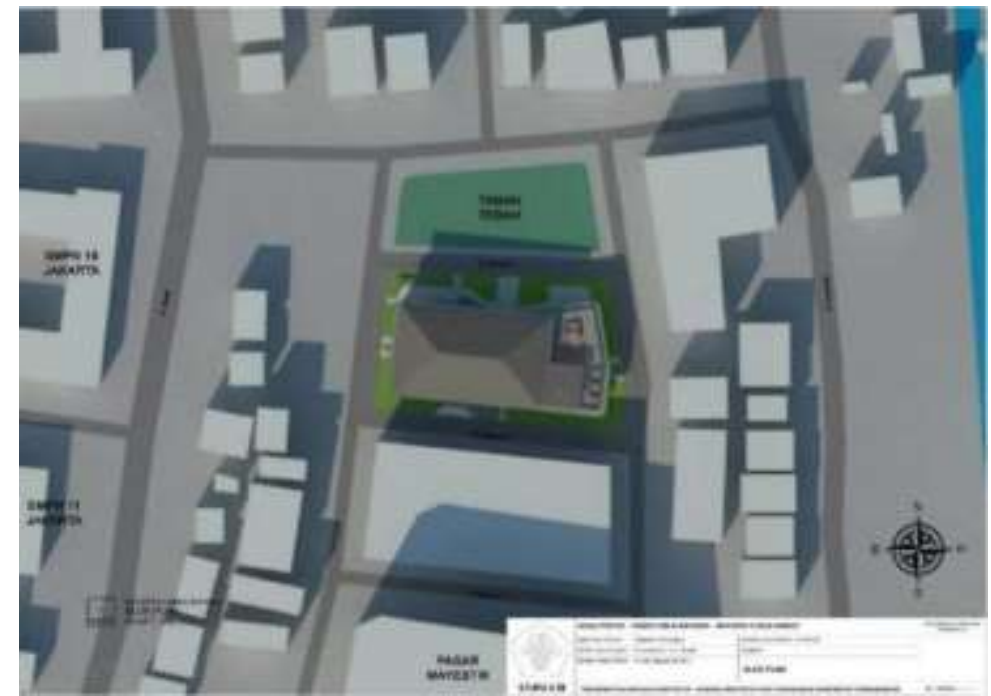

Gambar 3. Block Plan

Sumber: Penulis, 2020

Proyek terletak di kawasan Mayestik, tepatnya di JI. Tebah III. Kegiatan pada kawasan didominasi dengan kegiatan perdagangan melalui bangunan ruko 3 lantai dan pusat perbelanjaan Pasar Mayestik. Massa bangunan berorientasi ke utara, tepatnya mengarah ke Taman Tebah dengan alasan pencapaian dan visual baik dari dalam tapak ke luar dan juga dari luar tapak. Terdapat kegiatan lainnya seperti kegiatan sekolah melalui bangunan SMPN 11 Jakarta dan SMPN 19 Jakarta, dan juga kegiatan perumahan. 


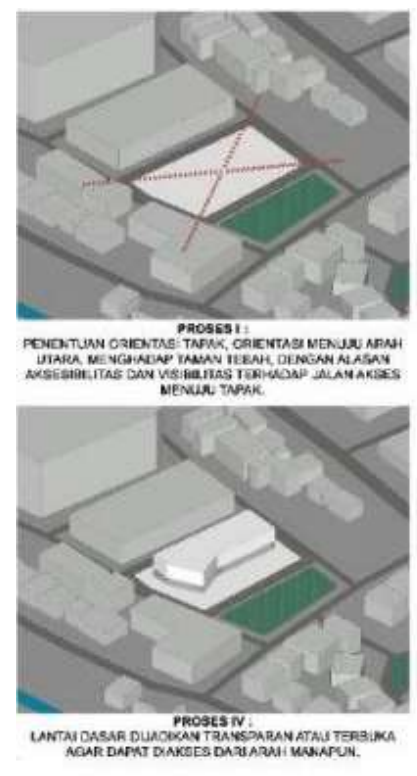

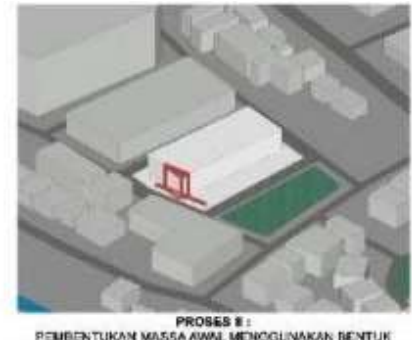
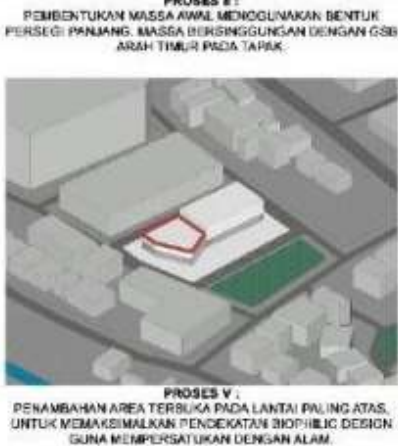

Gambar 4. Proses Gubahan Massa

Sumber: Penulis, 2020

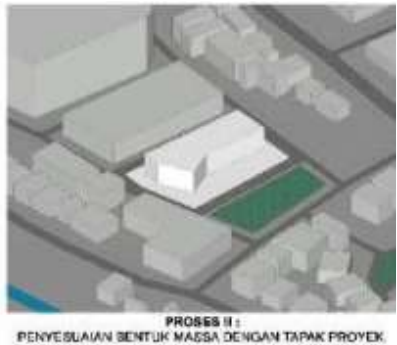

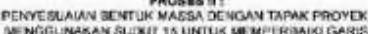

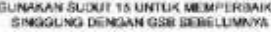

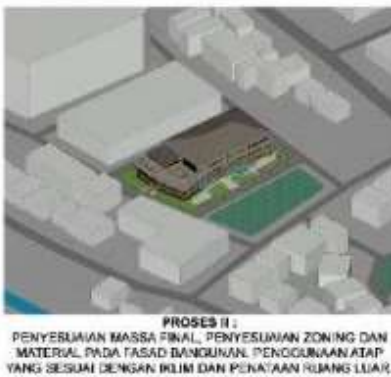

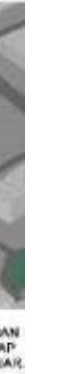

. 


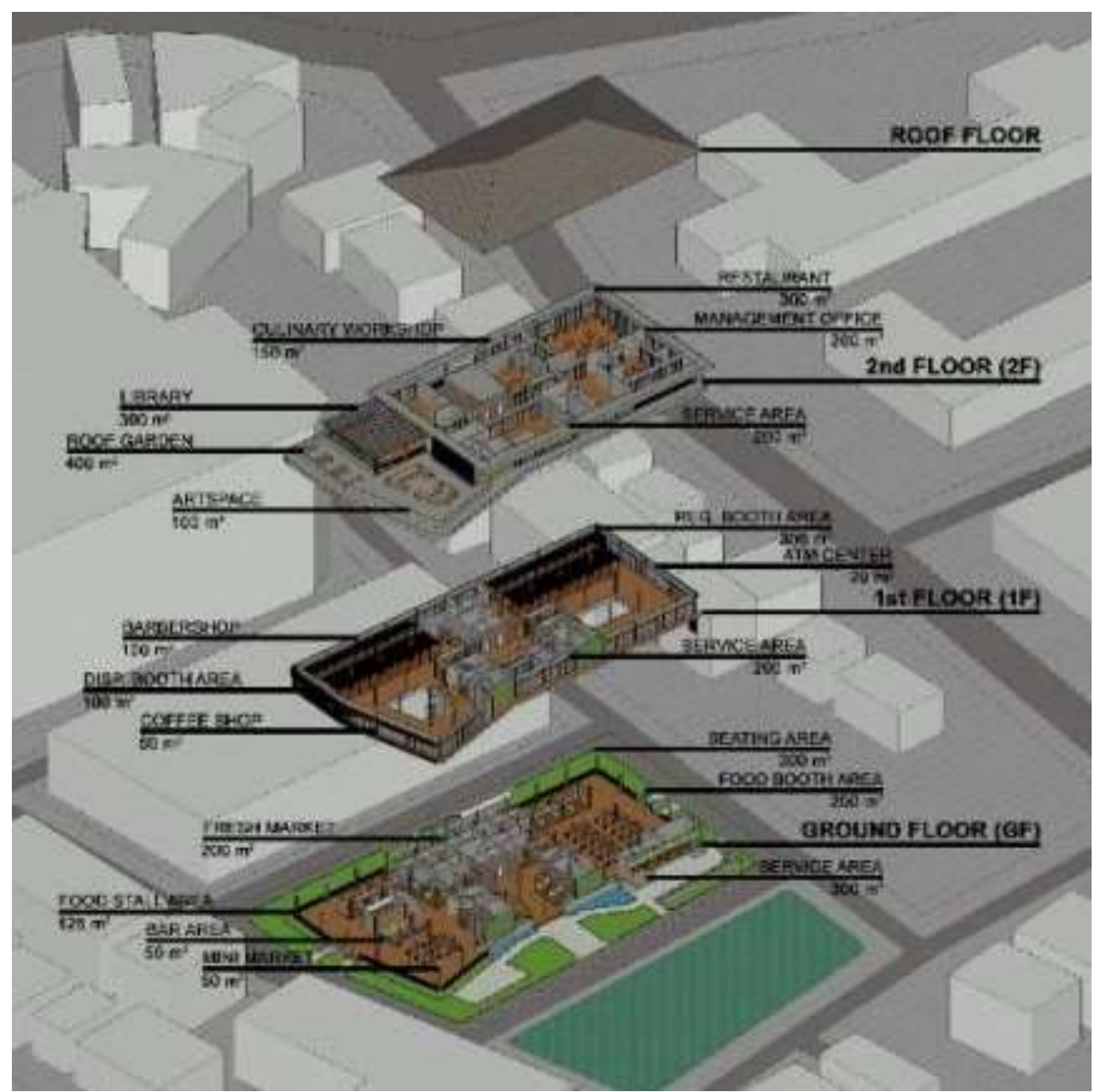

Gambar 5. Program

Sumber: Penulis, 2020

Setelah pemetaan program dan aktivitas selesai, maka dilanjutkan dengan pengolahan fasad bangunan yang memanfaatkan konsep biophilic design untuk memaksimalkan penggunaan unsur hijau atau alam pada bangunan. Hal ini untuk menjunjung poin sustainable develpoment goals nomor 15 yang berisi tentang Life on Land, dikarenakan Kebayoran Baru sendiri memiliki julukan Kota Taman akibat nilai historis rancangan kota ini, sehingga akan lebih baik jika unsur alam disematkan dalam fasad bangunan dan juga ruang dalam bangunan untuk mempertahankan nilai ini. Berikut akan ditampilkan fasad bangunan dilengkapi dengan keterangan unsur-unsur yang digunakan pada pengolahan tampak bangunan masing-masing beserta dengan alasannya.

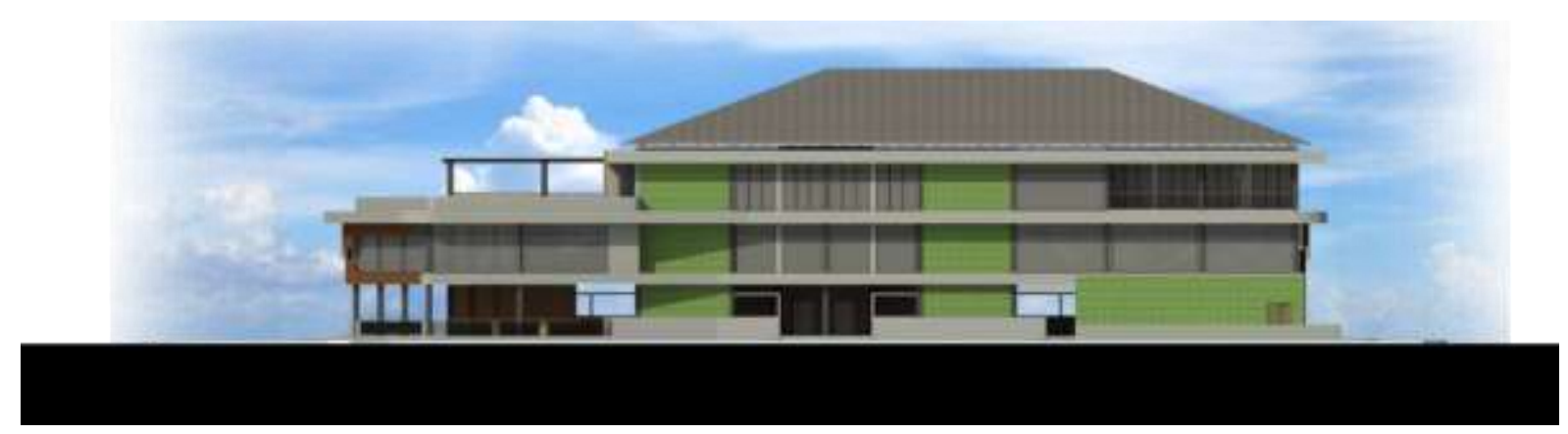

Gambar 6. Tampak Muka Proyek

Sumber: Penulis, 2020 
Pada tampak muka bangunan atau tampak utara, tidak menggunakan kisi-kisi kayu dan hanya menggunakan fasad dengan memanfaatkan tanaman hijau dan juga vertical garden pada dinding-dinding mati.Hal ini dikarenakan muka bangunan menghadap ke arah Taman Tebah yang dimanfaatkan sebagai view utama dari proyek ini.

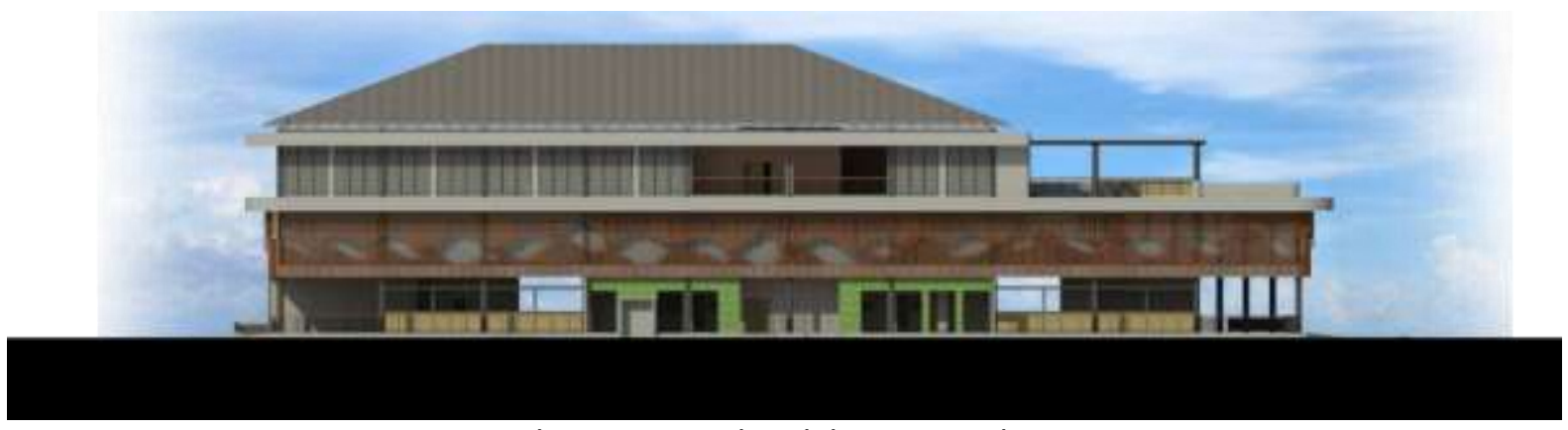

Gambar 7. Tampak Belakang Proyek Sumber: Penulis, 2020

Berbeda dengan tampak muka, tampak belakang lebih terkesan tertutup dengan adanya kisi-kisi kayu. Pada lantai dasar terdapat dinding yang berfungsi sebagai pemisah antara ruang dalam bangunan dengan area servis loading dan sampah.

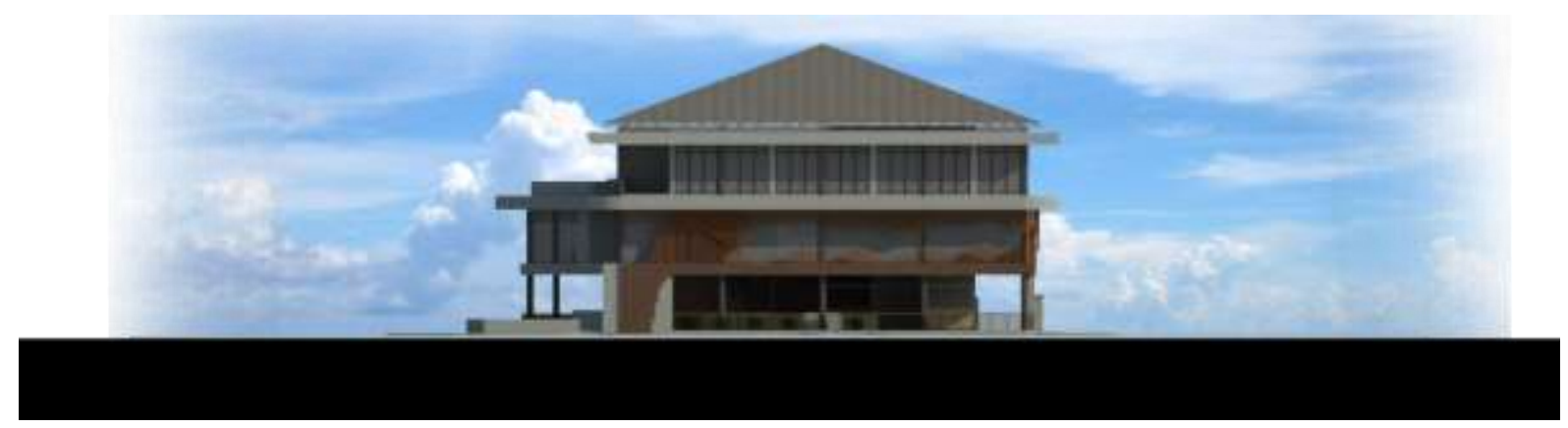

Gambar 8. Tampak Samping Kanan Proyek

Sumber: Penulis, 2020

Pada tampak samping kiri dan kanan juga menggunakan kisi-kisi kayu yang berfungsi sebagai shading terhadap sinar matahari alami yang masuk, sehinngga sinar matahari yang masuk tidak menyilaukan pengguna yang sedang berada di dalam bangunan.

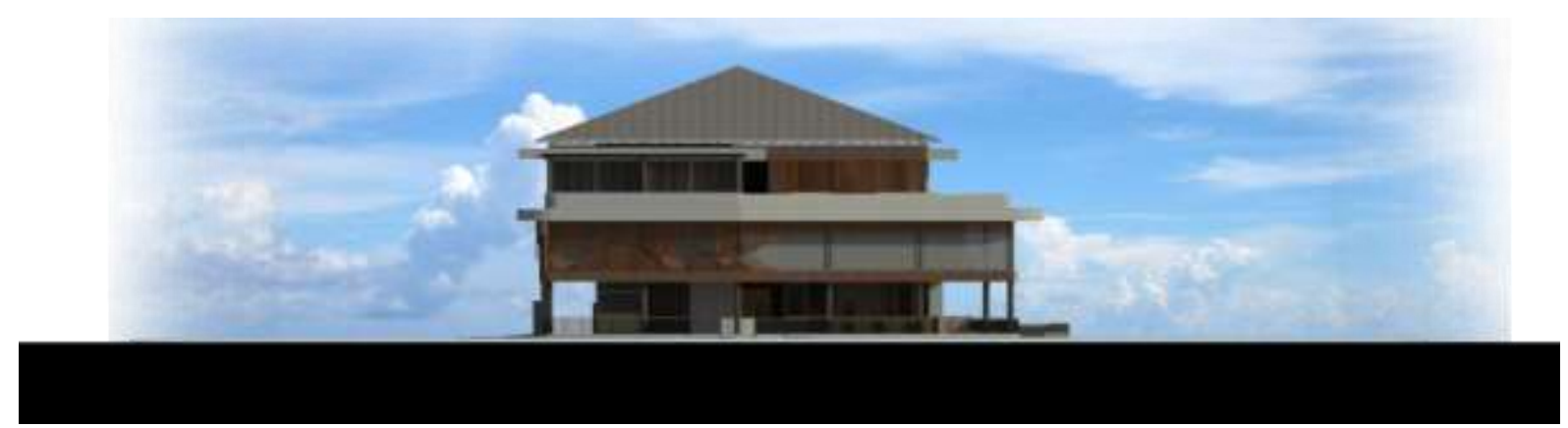

Gambar 9. Tampak Samping Kiri Proyek Sumber: Penulis, 2020

Berikutnya akan ditampilkan Tampak 3 dimensi pada eksterior dan interior bangunan. 


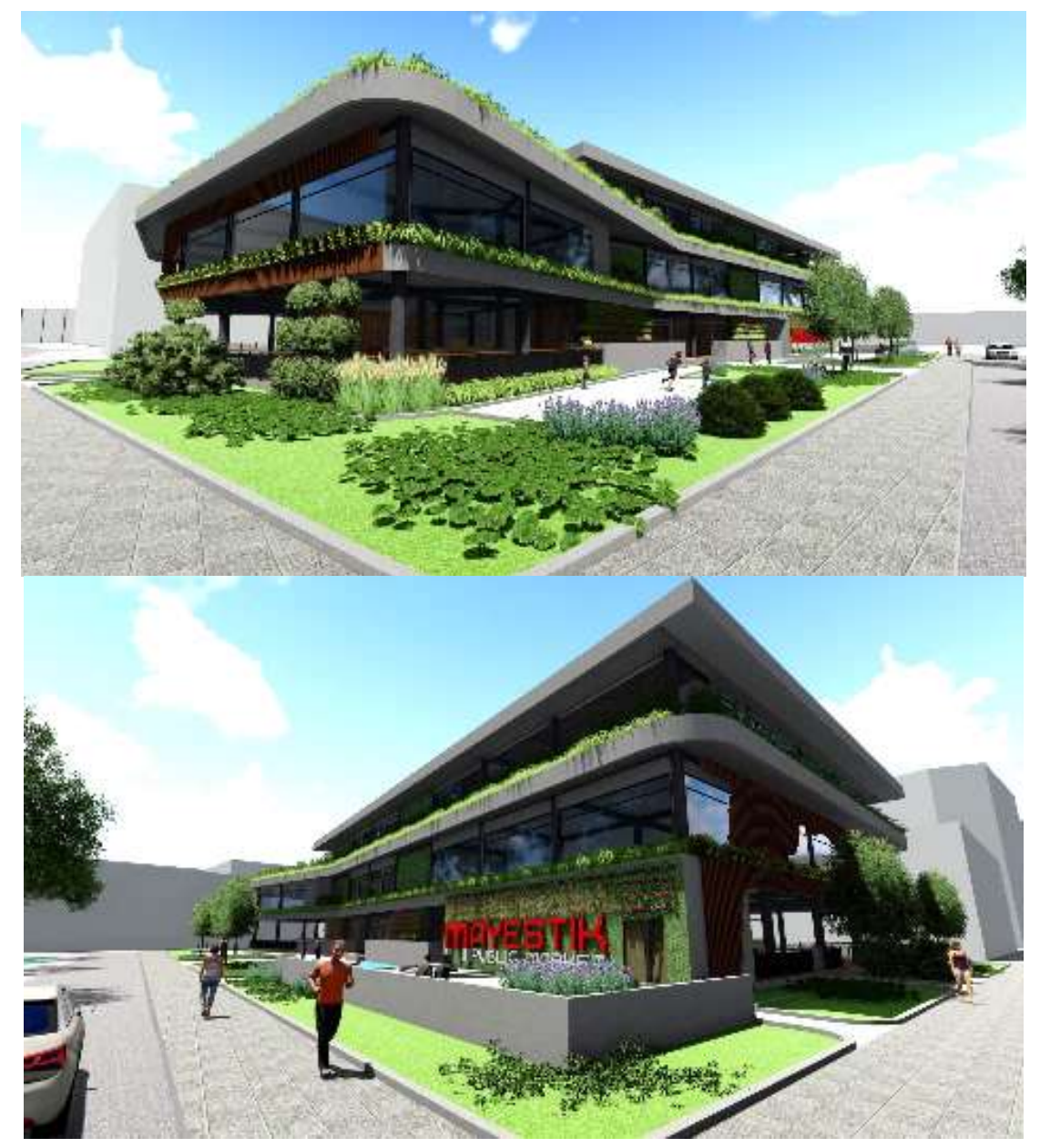

Gambar 10. 3D Eksterior Bangunan

Sumber: Penulis, 2020

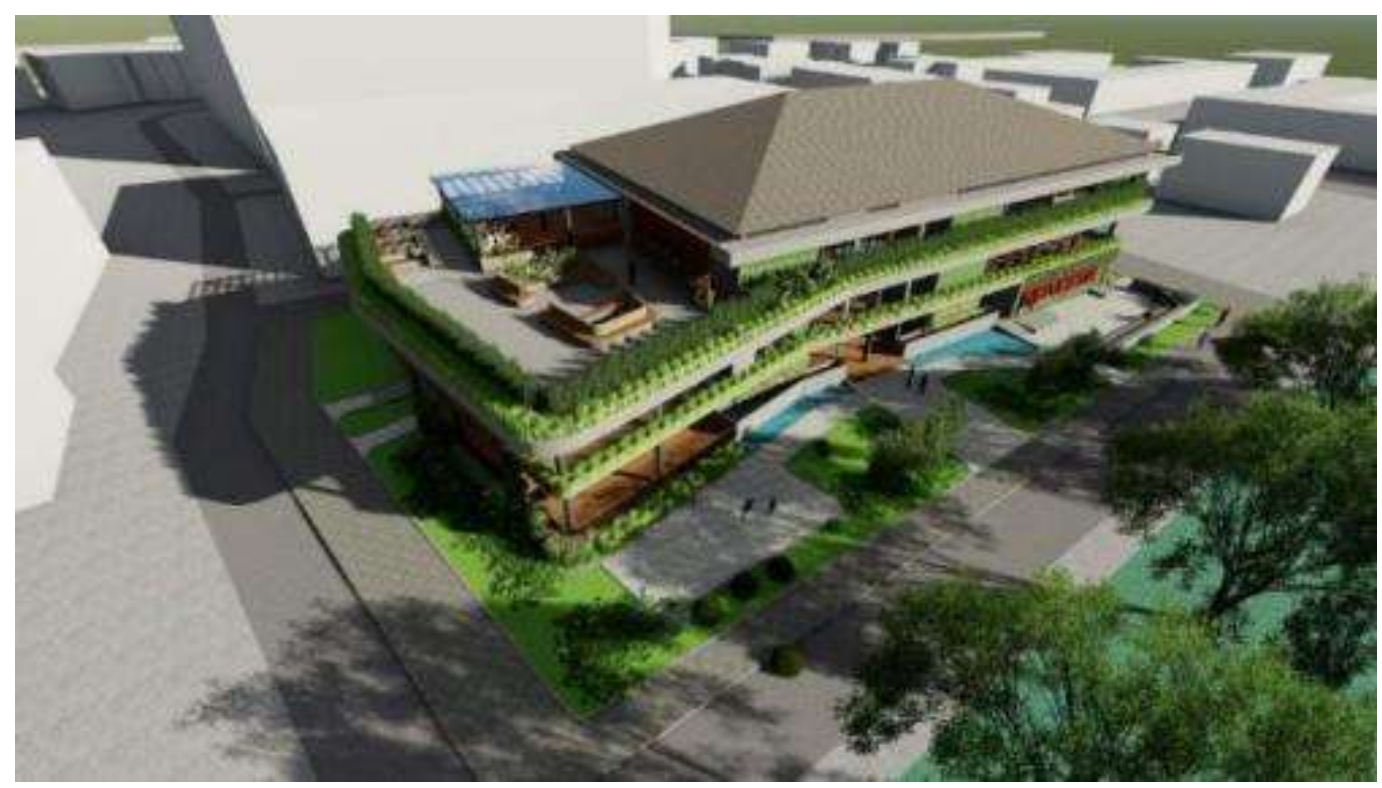

Gambar 11. 3D Bird Eye View Proyek

Sumber: Penulis, 2020 


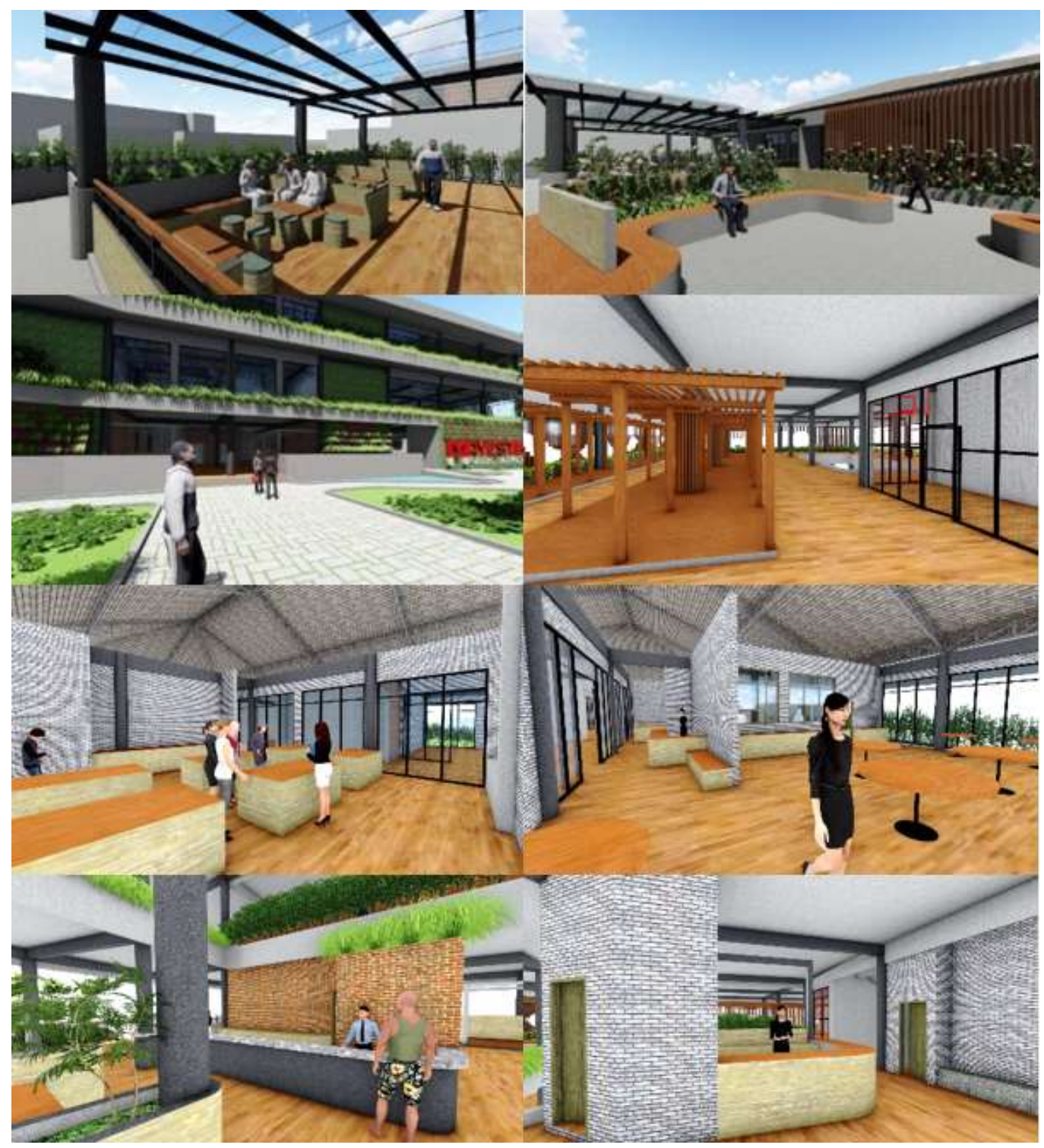

Gambar 8. 3D Interior Bangunan

Sumber: Penulis, 2020

\section{KESIMPULAN DAN SARAN Kesimpulan}

Proyek Pasar Publik Mayestik ini dibuat berdasarkan isu berupa kebutuhan masyarakat akan tempat atau wadah untuk bersosialisasi akibat gaya hidup masyarakat yang individualis dan keterikatan akan waktu akibat tuntutan pekerjaan ataupun aktivitas lainnya. Hal ini diakibatkan karena kurangnya tempat publik yang mampu untuk mewadahi kebutuhan masyarakat tersebut akibat lokasi yang kurang mendukung ataupun fasilitas dari wadah yang kurang mumpuni. Program ini memiliki 3 konsep utama, yaitu konsep Social Economy sebagai konsep platform kegiatan dalam program, konsep Permeabilitas sebagai konsep lokasi tapak proyek, dan konsep Biophilic Design sebagai konsep perancangan fasad bangunan.

Program ini juga dirancang untuk mendukung Sustainable Development Goals perihal poin nomor 10 tentang Reduced Inequalities dan poin nomor 15 tentang Life on Land. Hal ini tercerminkan dari rancangan program di dalam proyek dan juga rancangan terhadap fasad bangunan yang mendukung. Proyek Pasar Publik Mayestik ini dikategorikan sebagai komersial, yang merupakan tempat ketiga dari sebuah kawasan. Fasilitas utama dalam program ini lebih terfokuskan untuk aktivitas perdagangan barang dan jasa yang dikategorikan menjadi 2 area, 
yaitu area basah dan kering yang mewakili barang apa yang diperjualbelikan didalam area tersebut. Terdapat juga area-area komunal di dalam program utama ini untuk melakukan interaksi sosial ataupun diskusi hingga bermain. Terdapat juga program-program penduking lainnya yang bertujuan untuk pengembangan diri dan juga untuk berinteraksi sosial. Tempat ini ditujukan bagi orang-orang yang membutuhkan tempat untuk berdagang dan juga tempat untuk berinteraksi yang menyesuaikan gaya hidup modern masyarakat yang krisis terhadap waktu.

\section{Saran}

Pengolahan ruang dapat lebih dimaksimalkan sesuai dengan karakteristik program atau fungsi yang ada didalamnya, baik dari layout zoning dan volume ruangan serta perancangan utilitas bangunan dapat dikembangkan atau dimaksimalkan dengan menggunakan elemen Green Architecture untuk memanfaatkan penanggulangan energi yang digunakan di dalam bangunan proyek ini untuk penghematan energi.

\section{REFERENSI}

Antener, J. (2019). Third Space: When Cultures Mix and Merge. Diunduh 21 Januari 2020, $<$ https://thirdspace-webseries.com/

Bhabha, H. K. (2004). The Location of Culture. Abingdon: Routledge

Carmona, M. (2003). Public Places- Urban Spaces, The Dimension of Urban Design. Routledge

Chase, R. (2015). Peers Inc.. USA: BBS PublicAffairs

McLaren, D., Agyeman, J. (2015). Sharing Cities: A Case for Truly Smart and Sustainable Cities.

USA: MIT press

Oldenburg, R. (1999). The Great Good Place. USA: Da Capo Press

Sustainable Development Goals (2019). Goal 10: Reduced Inequalities. Diunduh 21 Januari 2020, <https://www.un.org/sustainabledevelopment/inequality/

Sustainable Development Goals (2019) Goal 15: Life on Land. Diunduh 21 Januari 2020, $<$ https://www.un.org/sustainabledevelopment/biodiversity/

Tuan, Y. F. (1977). Space and Place: the persepective of experience. Minneapolis: University of Minnesota

Zaretsky, A. (2017). Public Market Development: What is Public Market?. Diunduh 21 Januari 2020, <https://publicmarketdevelopment.com/what-is-a-public-market-2/ 